\title{
Normative data of left ventricular mass index in middle aged population of Vidarbha
}

\author{
Manoj Jiwtode \\ Associate Professor, Dept. of Physiology, Government Medical College, Hanuman Nagar, Nagpur, Maharashtra, India
}

*Corresponding Author:

Email: manoj_jiwtode123@rediffmail.com

\begin{abstract}
Patients with left ventricular hypertrophy (LVH) are more prone to cardio-vascular events than one without LVH. Hence it is important to detect left ventricular hypertrophy at an early stage. Left ventricular hypertrophy denotes increase in mass of left ventricle (LVM). Variety of factors influences left ventricular hypertrophy including various anthropometric parameters. Since LVM is significantly correlated with body surface area (BSA). Left ventricular mass is routinely indexed for body surface area to calculate LVM Index (LVMI). LVMI gives information about presence or absence of left ventricular hypertrophy. In this study 120 normotensive subjects including male and female who were free from any diseases were selected. BSA of participants was measured; the mean value was $1.64 \mathrm{~m}^{2}$. Left Ventricular Mass was estimated by 2-D-Echocardiography, the mean value was 143.38 g. We observed Left Ventricular Mass was significantly correlated with Body Surface Area. Left Ventricular Mass was indexed for Body Surface Areato determines normal range of Left Ventricular Mass using LVM Index. The normal limits of Left Ventricular Mass Index were between 83.95 to $89.69 \mathrm{~g} / \mathrm{m}^{2}$.
\end{abstract}

Keywords: Echocardiography, Left ventricular mass, Body surface area, Left ventricle mass Index.

\section{Introduction}

Among heart diseases Coronary Artery Disease $(\mathrm{CAD})$ is the most common fatal disease. One of the important risk factor for development of CAD is hypertension. India is no exception to it, it is also following the same trend. With passage of time there is heavy increment in the cases of CAD. Majority of deaths in this situation are attributed to complication of hypertension i.e. Left ventricular hypertrophy (LVH). LVH denotes increase in the mass of left ventricle associated with hypertrophy of individual muscle fiber. ${ }^{1-4}$ In general Heart responds to hypertension i.e. increase in afterload by increase in wall thickness of chamber and increasing its mass. Early diagnosis of LVH is important to prevent complications like Arrhythmia, Myocardial Infarction and Sudden death. ${ }^{1,5-7}$ Echocardiography offers diagnosis of LVH by measuring wall thickness and by calculating left ventricular mass (LVM).

Many factors such as age, sex, race, dietary sodium intake, insulin resistance, adrenergic stimulation have already been positively correlated with LVM and shown to promote LVM. ${ }^{8-11}$ Anthropometric factors like height, weight, BSA and BMI also positively correlate with LVM but BSA correlated more strongly. Increasing BSA Increases LVM. Hence for reducing variance among normal subjects LVM is indexed for BSA to get normal values in the form of LVM index. The aim of present study was to study normal limits of LVM using LVMI.

\section{Materials and Methods}

In this study 120 normotensive subjects in the age group of 35 to 65 yrs were selected from O.P.D. of
Medicine. Out of 120, 62 were males and 58 were female. Written consent was taken from each of the subject. Permission of Institutional Ethical Committee was taken. Following inclusive criteria were applied:

1. Age between 35 to $65 \mathrm{yrs}$

2. Systolic BP $<140 \mathrm{mmHg}$

3. Diastolic BP $<90 \mathrm{mmHg}$

4. No Overt evidence of cardio-vascular disease

5. No diabetes

Cardiovascular diseases were ruled out by history taking and clinical examination. Diabetes was ruled out by estimating random blood sugar level. Each participant was subjected to measurement of height in $\mathrm{cm}$ and weight in $\mathrm{Kg}$. Each participant was subjected to detailed history taking followed by careful clinical examination. B.P. was recorded in supine position after15 minute of rest. Both Systolic and Diastolic B.P. were recorded. All the individuals were subjected to Mmode echocardiographic examination, done on acuson computed sonography $128 \times \mathrm{P} / 10 \mathrm{c}$ echocardiography machine $2.5 \mathrm{MHz}, 13 \mathrm{~mm}$ transducer was used. It was done as per recommendation of American Society of Echocardiography (ASE). ${ }^{12}$ In each individual Left Ventricular Internal Diameter at end diastole (LVIDd), Left Ventricular Posterior wall thickness at end diastole (PWTd) and Inter Ventricular Septal Thickness at end Diastole (IVSd) were noted. As per recommendation of ASE thickness of Right and left septal endocardial echoes were included in IVS and posterior endocardial echoes were included in Left ventricular posterior wall. LVIDd did not include septal and posterior wall endocardial echoes, it was the maximum distance from 
left ventricular posterior wall endocardium and left septal endocardium.

The normal measurements are ${ }^{13}$ :
1. IVSd thickness
6 to $11 \mathrm{~mm}$
2. PWTd thickness
6 to $11 \mathrm{~mm}$
3. LVIDd
35 to $57 \mathrm{~mm}$

With above recorded data, LVM was automatically calculated by echocardiography machine using "ASE (corrected) cube formula ${ }^{6}$ i.e.

$$
\begin{aligned}
& \mathrm{LVM}=0.8\left[1 . 0 4 \left\{(\mathrm{LVIDd}+\mathrm{IVSd}+\mathrm{PWTd})^{3}-(\mathrm{LVIDd})^{3}\right.\right. \\
& \}]+0.6 \mathrm{~g}
\end{aligned}
$$

LVM is expressed in gram (g).

Apart from LVM, the body surface area of all individuals were calculated by using Du Bois' formula $(1916)^{14}$

i.e. $\mathrm{BSA}=0.0001 \times 71.84$ (weight in $\mathrm{Kg})^{0.425} \times$ (height in $\mathrm{cm})^{0.725}$. BSA expressed in Square meter $\left(\mathrm{m}^{2}\right)$.

\section{Statistical Analysis}

Simple correlation test was used to assess the association between LVM and BSA. Statistical software STATA version 14.0 was used for statistical analysis. Indexation of LVM for BSA was done to calculate LVM index (LVMI). It is expressed as $\mathrm{g} / \mathrm{m}^{2}$.

\section{Results}

In the present study various parameters viz. BSA, LVM and LVMI were studied in total 120 subjects. All the subjects were in the range of 35 to $65 \mathrm{yrs}$ of age. Their physical characteristics were noted in the form of age, height and weight. The BSA was calculated from $\mathrm{Du}$ Bois' formula. LVM was calculated by Echocardiography machine by using ASE corrected cube formula. LVMI was calculated by dividing LVM by BSA ${ }^{(15-22)}$. Out of 120 subjects 62 were male and 58 were female (Table 1).

Table 1: Summary statistics of study parameters of all subjects

\begin{tabular}{|l|c|c|c|c|c|c|c|}
\hline \multicolumn{1}{|c|}{ Parameter } & Number & Mean & Median & SD & SEM & \multicolumn{2}{|c|}{ 95\% C.I. } \\
\hline Age $(\mathrm{Yrs})$ & 120 & 48.72 & 49 & 7.87 & 0.72 & 47.29 & 50.14 \\
\hline Height $(\mathrm{cm})$ & 120 & 160.35 & 160 & 6.49 & 0.59 & 159.18 & 161.53 \\
\hline Weight $(\mathrm{kg})$ & 120 & 61.58 & 62 & 7.88 & 0.72 & 60.16 & 63.01 \\
\hline BSA $\left(\mathrm{m}^{2}\right)$ & 120 & 1.64 & 1.65 & 0.12 & 0.01 & 1.62 & 1.66 \\
\hline $\begin{array}{l}\text { Systolic BP } \\
(\mathrm{mmHg})\end{array}$ & 120 & 128.77 & 130 & 7.79 & 0.71 & 127.36 & 130.18 \\
\hline $\begin{array}{l}\text { Diastolic BP } \\
(\mathrm{mmHg})\end{array}$ & 120 & 80.58 & 82 & 5.57 & 0.51 & 79.58 & 81.59 \\
\hline IVSd $(\mathrm{mm})$ & 120 & 8.60 & 8 & 1.44 & 0.13 & 8.34 & 8.86 \\
\hline PWId $(\mathrm{mm})$ & 120 & 8.49 & 9 & 1.47 & 0.13 & 8.22 & 8.76 \\
\hline LVID $(\mathrm{mm})$ & 120 & 48.09 & 49 & 4.16 & 0.38 & 47.34 & 48.85 \\
\hline LVM $(\mathrm{g})$ & 120 & 143.38 & 143.12 & 31.69 & 2.89 & 137.65 & 149.10 \\
\hline LVMI $\left(\mathrm{g} / \mathrm{m}^{2}\right)$ & 120 & 86.82 & 87.12 & 15.86 & 1.45 & 83.95 & 89.69 \\
\hline
\end{tabular}

Table 2: Summary statistics of study parameters of Male subjects

\begin{tabular}{|l|c|c|c|c|c|c|c|}
\hline Parameter & Number & Mean & Median & SD & SEM & \multicolumn{2}{|c|}{ 55\% C.I. } \\
\hline Age $(\mathrm{Yrs})$ & 62 & 48.77 & 49 & 7.89 & 1.00 & 46.77 & 50.78 \\
\hline Height $(\mathrm{cm})$ & 62 & 163.21 & 1.65 & 5.7 & 0.73 & 161.76 & 164.66 \\
\hline Weight $(\mathrm{kg})$ & 62 & 62.89 & 64.5 & 9.24 & 1.17 & 60.54 & 65.23 \\
\hline BSA $\left(\mathrm{m}^{2}\right)$ & 62 & 1.68 & 1.71 & 0.13 & 0.02 & 1.64 & 1.71 \\
\hline $\begin{array}{l}\text { Systolic BP } \\
(\mathrm{mmHg})\end{array}$ & 62 & 129.16 & 130 & 8.05 & 1.02 & 127.12 & 131.21 \\
\hline $\begin{array}{l}\text { Diastolic BP } \\
(\mathrm{mmHg})\end{array}$ & 62 & 80.39 & 82 & 6.04 & 0.77 & 78.85 & 81.92 \\
\hline IVSd (mm) & 62 & 9.02 & 9 & 1.75 & 0.22 & 8.57 & 9.46 \\
\hline PWId (mm) & 62 & 8.74 & 9 & 1.77 & 0.23 & 8.29 & 9.19 \\
\hline LVID $(\mathrm{mm})$ & 62 & 48.44 & 49 & 4.57 & 0.58 & 47.27 & 49.60 \\
\hline LVM $(\mathrm{g})$ & 62 & 152.53 & 152.47 & 35.52 & 4.51 & 143.51 & 161.55 \\
\hline LVMI $\left(\mathrm{g} / \mathrm{m}^{2}\right)$ & 62 & 90.44 & 90.16 & 18.54 & 4.51 & 86.50 & 94.39 \\
\hline
\end{tabular}

Table 3: Summary statistics of study parameters of Female subjects

\begin{tabular}{|l|c|c|c|c|c|c|c|}
\hline Parameter & Number & Mean & Median & SD & SEM & \multicolumn{2}{|c|}{ 95\% C.I. } \\
\hline Age (Yrs) & 58.00 & 48.66 & 50 & 7.93 & 1.04 & 46.57 & 50.74 \\
\hline Height $(\mathrm{cm})$ & 58.00 & 157.30 & 1.59 & 5.89 & 0.77 & 155.75 & 158.85 \\
\hline Weight $(\mathrm{kg})$ & 58.00 & 60.19 & 62 & 5.87 & 0.77 & 58.65 & 61.73 \\
\hline
\end{tabular}




\begin{tabular}{|l|c|c|c|c|c|c|c|}
\hline BSA $\left(\mathrm{m}^{2}\right)$ & 58.00 & 1.60 & 1.63 & 0.11 & 0.01 & 1.58 & 1.63 \\
\hline $\begin{array}{l}\text { Systolic BP } \\
(\mathrm{mmHg})\end{array}$ & 58.00 & 128.34 & 130 & 7.55 & 0.99 & 126.36 & 130.33 \\
\hline $\begin{array}{l}\text { Diastolic BP } \\
(\mathrm{mmHg})\end{array}$ & 58.00 & 80.79 & 80 & 5.505 & 0.66 & 79.46 & 82.12 \\
\hline IVSd $(\mathrm{mm})$ & 58.00 & 8.16 & 8 & 0.81 & 0.11 & 7.94 & 8.37 \\
\hline PWId $(\mathrm{mm})$ & 58.00 & 8.22 & 8 & 1.02 & 0.13 & 7.95 & 8.49 \\
\hline LVID $(\mathrm{mm})$ & 58.00 & 47.72 & 49.5 & 3.68 & 0.48 & 46.76 & 48.69 \\
\hline LVM $(\mathrm{g})$ & 58.00 & 133.59 & 139.19 & 23.62 & 3.10 & 127.37 & 139.80 \\
\hline LVMI $\left(\mathrm{g} / \mathrm{m}^{2}\right)$ & 58.00 & 82.76 & 86.07 & 11.18 & 1.47 & 79.82 & 85.70 \\
\hline
\end{tabular}

These subjects were having BSA in the range of $1.2979 \mathrm{~m}^{2}$ to $1.9637 \mathrm{~m}^{2}$. LVM was in the range of $66.4685 \mathrm{~g}$ to $248.6732 \mathrm{~g}$. When BSA of all the subjects were compared with observed LVM, we found that there is a highly significant association between BSA and LVM ( $\mathrm{r}=0.6797, \mathrm{p}<0.0001)$ indicating that as the BSA increased LVM also increased. Normal limits of LVM were calculated by using LVMI for both the genders. For male it was between 86.50 to $94.39 \mathrm{~g} / \mathrm{m}^{2}$ and for female it was between 79.82 to $85.70 \mathrm{~g} / \mathrm{m}^{2}$ (Table 2 and Table 3 ).

\section{Discussion}

The present study was aimed to study normal limits of LVM using LVMI. The subjects were in the age group of 35 to 65 yrs. The methodology was set taking into the consideration the influence of other factors on LVM viz. Age, weight, height, and B.P. The subjects with normal B.P. (Mean Systolic B.P. $128.77 \mathrm{mmHg}$ and Mean Diastolic B.P. $80.58 \mathrm{mmHg}$ ) were selected so as to avoid the influence of hypertension on LVM. ${ }^{7,16,20,23-25}$

The BSA of this group was in the range of $1.2979 \mathrm{~m}^{2}$ to $1.9637 \mathrm{~m}^{2}$. The mean BSA was $1.64 \mathrm{~m}^{2}$. In the present study the mean value of LVM was $143.38 \mathrm{~g}$. The values of BSA of all subjects were correlated with LVM. It was seen that the BSA had a strong positive correlation with LVM ( $\mathrm{r}=0.827, \mathrm{p}<0.0001)$. The result of our study was consistent with findings of various studies of Howard P. et al, ${ }^{26}$ Richard B. Devreux, ${ }^{15}$ Daniel Levy et al, ${ }^{18}$ J.C. Mohan et al, ${ }^{21}$ I W Hammond et $\mathrm{al}^{(16)}$, Stephen Daniel et $\mathrm{al}^{19}$ and Daniel Savage et al. $^{20}$

The probable reason for increase in LVM with increase in BSA is that between birth and adulthood BSA increases by nine fold (from about 0.2 to $1.8 \mathrm{~m}^{2}$ ). ${ }^{26}$ Cardiac measurements increase as an exponential function of surface area, for linear measurements such as left ventricular end diastolic diameter is mainly affected. The result of our study showed that it was LVIDd that increased with increase in BSA. This result was consistent with the results of Lester et al, ${ }^{27}$ Henry et al, ${ }^{28}$ Devreux et al, ${ }^{6}$ Graham ${ }^{29}$ and Lange. ${ }^{30}$

\section{Normal limits of LVM}

The LVM is influenced by various factors like age, sex, race, body habitus, blood pressure and many others. It is very difficult to draw normal limits of LVM. It is then necessary to incorporate into the definition the normal characteristics of subjects that correlate strongly with LVM and helps in reducing variance among normal subjects. That Characteristic is BSA. By this approach we have determined that indexation of LVM for BSA is valuable. Indexation of LVM for BSA is termed as Left Ventricular Mass Index (LVMI). It is expressed as $\mathrm{g} / \mathrm{m}^{2}$. In our study mean value of LVM was $143.38 \mathrm{~g}$ and mean value of BSA was $1.64 \mathrm{~m}^{2}$. Using these two parameters mean LVMI for both genders came as $86.82 \mathrm{~g} / \mathrm{m}^{2}$, for males as 90.44 $\mathrm{g} / \mathrm{m}^{2}$ and for females as $82.76 \mathrm{~g} / \mathrm{m}^{2}$.

From the observations and result of our study, we can conclude that the normal limits of LVM in our study using LVMI for both genders are between 83.95 to $89.69 \mathrm{~g} / \mathrm{m}^{2}$, for males it was between 86.50 to 94.39 $\mathrm{g} / \mathrm{m}^{2}$ and for females it was between 79.82 to 85.70 $\mathrm{g} / \mathrm{m}^{2}$. Taking these findings into consideration we suggest similar experimental studies with large sample size for getting accurate values of LVM in normal healthy population which can enable us to diagnose left ventricular hypertrophy at the earliest to prevent its complications.

\section{Acknowledgement}

Staff of Department of Cardiology

,Superspeciality Hospital, Govt. Medical College and Hospital, Nagpur, Maharashtra, India.

\section{References}

1. Casale PM, Devereux RB, Milner N. value of Echo measurements of LV Mass in predicting cardiovascular morbid events in hypertensive men. Ann Of Intern Med 1986;105:173-8.

2. Troy BL, Pombo J, Rackley CE. Measurement of left ventricular wall thickness and mass by Echocardiography. Circulation 1972;45:602-11.

3. Reichek N, Devereux RB. Left ventricular hypertrophy: Relations of anatomic echocardiographic and electrocardiographic findings. Circulation 1981;63:13918.

4. Devereux RB, Reichek N. Echocardiographic determination of left ventricular mass in man. Anatomic validation method. Circulation 1977;55:613-18. 
5. Garrison D. Levy, Savage DD, Kannel WB. Prognostic implications of echocardiographically determined LVM in Framingham Heart Study. N Engl J Med 1990;322:1561-6.

6. Devereux RB, V Daniel Alonso. Echocardiographic assessment of LVH: Comparison to necropsy findings. Am. J. Cardiology 1986;57:450-8.

7. Drayer Jim, Henry WL, Savage DD. Echocardiographic assessment of cardiac anatomy and functions in hypertensive subjects. Ciculation 1979;59:623-32.

8. Frohlich ED, Apstein C. The heart in hypertension. N Engl J Med 1992;327:998-1008.

9. Gottdiener JS, Reda DJ. Importance of Obesity, race and age to cardiac structural and functional effects of Hypertension. J. Am. Col Cardiol 1987;10:1280-85.

10. Kupari M, Koskinen P. Correlates of left ventricular mass in population sample aged 36 to 37 yrs: focus on lifestyle and salt intake. Circulation 1994;89:1041-50.

11. Leibson JP. Echo cardiographic correlates of LV structure among 844 mildly hypertensive men and women in treatment of mild hypertension study (TOMHS). Circulation 1993;87:476-86.

12. Sahn DJ, De Maria A, Kisslo J. The Committee on MMode Standardization of American society of Echocardiography: Recommendations regarding qualification in M-Mode Echocardiography: result of survey of echocardiographic measurements. Circulation1978;58:1072-81.

13. Panda UM. Clinical Cardiology 1995. Pediatr Cardiol 1982;3:205-11.

14. Dubois D, Dubois EF. A formula to estimate Body Surface Area if weight and height are known. Arch Intern Med 1916;17:863-71.

15. Devereux RB, Elizabeth ML, Paul NC. Standardization of M-mode Echocardiographic Left ventricular anatomic measurements. J. Am. Col Cardiol 1984;4(6):1222-30.

16. Hammond IW, Devereux RB, Michel Alkerman. The prevalence and correlates of Left ventricular hypertrophy among employed patients with uncomplicated hypertension. J. Am Col Cardiol 1988;12:996-1004.

17. Savage DD, Garrison RJ. The spectrum of Left ventricular hypertrophy in general population sample: The Framingham Study. The Circulation 1987; Suppl. I: $126-35$.

18. Daniel Levy. Echocardiographic criteria for left ventricular hypertrophy: The Framingham Heart Study. Am. J. Cardiol 1987;59:956-60.

19. Stephen Daniels, Richard AM. Echocardiographicaly determined LV mass Index in normal children, adolescent and young adults. J Am Col. Cardiol 1988;12:703-8.

20. Savage Daniel, Daniel Levy. Association of Echocardiographic left ventricular mass with body size, blood pressure and physical activity (The Framingham Study). Am J Cardiol 1990;65:371-6.

21. Mohan JC, GS Ravi Prasad, P Arora. Left ventricular mass in normal Indian adults and its correlation with anthropometric parameters. Indian J. Med. Res. August, 1991;94:286-9.

22. Andrea A Brandao, Roberto Pozzan. Role of Anthropometric indices and blood pressure as determinants of left ventricular mass and geometry in adolescents. The Rio de Janeiro study. Hypertension 1995;26(part 2):1190-4.

23. Rowland DB, DR Glover. Assessment of LVM and its response to anti hypertension treatment. Lancet1982;I:467-70.

24. Devereux RB. Left ventricular mass in hypertension. Lancet 1982;1:1021-22.
25. Claudia HRM Costa, Marcelo C. Bastista. Serum insulin level, 24 hrs BP profile and LVM in Nonobese hypertensive patients. Hypertension 1995;26(Part 2):1085-88.

26. Howard P Gutgesell, Christopher M. Rembold. Growth of Human heart relative to Body Surface Area. Am. J. Cardiol 1990;65:662-8.

27. Lester LA, Arcilla RA. M-Mode Echocardiograph in normal children and adolescents: Some new perspective. Paeditr. Cardiol 1987;8:27-33.

28. Henry WL, Ware JH. Echocardiographic measurements in normal subjects from infancy to old age. Circulation 1980;62:1054-61.

29. Graham TP. Left heart volume estimation ininfancy and childhood. Revaluation of methodology and normal values. Circulation 1971;43:895-904.

30. Lange PE, Onnasch DGW. Size and function of human left and right ventricles during growth: Normative angiographic data. Pediatr Cardiol 1982;3:205-1. 